\title{
Managing Diversity in Israel: Some Applications for South Africa
}

\section{R J Petersen and L P Vermeulen}

Department of Human Resource Management, University of Pretoria

\begin{abstract}
The management of diversity manifests itself in a very specific way in Israeli society. This is so because the management process occurs at two levels: a national-political level (first order processes) and the individual enterprise level (second order processes). The interactive nature of the two processes ultimately results in most diverse national groups working together productively towards both nationaleconomic and individual goals. Inclusiveness is a property widely found in the average Israeli enterprise. The purpose of this paper is to describe the unique Israeli approach to the management of their diverse workforce, with a view to identifying possible applications for South Africa. The study shows that South Africa has a lot to learn before we can hope to succeed in effectively managing our diverse rainbow nation.
\end{abstract}

JEL M 12

\section{INTRODUCTION AND OBJECTIVE}

South Africa is a country in transition. During this phase of radical change, issues such as workplace democracy, affirmative action and employee equity are high on the strategic agenda of most South African organizations. The strategic processes have already had an impact on the competitiveness of many companies. It is widely accepted that the future success of South African enterprises in the highly competitive international business community will largely depend on their ability to manage these transformational processes in a rapidly changing business and societal environment. This will go hand in hand with their efforts to develop and use the diverse talents of the so-called rainbow workforce. 
Achieving competitive advantage through (diverse) personnel is becoming a key management reality. As more South African companies operate across national and cultural borders, managing diversity is moving from being a social ideal to being a practical business mandate (Thomas, 1996:17). At national-strategic level it is crucially important for South African authorities to contribute positively to a national climate in which the diverse talents of all population groups can be harnessed and available skills fully used. Some captains of industry are understandably worried that politically inspired interference and intervention, such as forced affirmative action, could have the opposite effect and mean a further competitive setback for South African enterprises within the international business environment, due to its adverse effect on productivity. Although most business leaders regard affirmative action and black empowerment as necessary, they are of the opinion that the private sector should not be forced to give jobs to the disadvantaged, but should be allowed to focus on creating wealth and economic opportunity (Jeffery, 1996:11-13).

lsrael is a nation with a highly diverse population characterized by many religious, cultural and social groups, brought about by the fact that the state of Israel has since its inception in 1948 applied a national policy of encouraging Jewish people from all over the world to return to their ancient Biblical homeland. The purpose was to strengthen the newly formed state militarily and to give expression to the Zionist vision of recreating a home for persecuted Jewish communities which were literally spread all over the world after the destruction of Jerusalem in the year 70 . This policy resulted in the mass immigration and relocation of millions of Afro-Asian and American-European Jews to Israel over the past 50 years. Having lived among a diversity of foreign cultures for centuries, these people brought with them the diverse ethno-cultural practices of their countries of origin, which challenged the Israeli authorities to mould them into a new nation and utilize their diversity as a national asset ( Hirsh, 1993:195).

National efforts to manage this diversity have been remarkably successful. Strategic government plans for absorbing immigrant groups and integrating them into Israeli society, created the basis for the effective management of diversity in the community at large. Such intervention established a national climate conducive to the management of diversity which spills over into the Israeli workplace, thus providing management with all the necessary ingredients to create/add value by utilizing the benefits of this diversity.

The purpose of this article is to describe the Israeli approach to managing diversity, with the view to identifying possible applications for South Africa. 


\section{MEANING OF THE CONCEPT "MANAGING DIVERSITY"}

Workforce diversity refers to those differences in an enterprise or organization that have an influence on the performance of the workforce. These differences are not limited to colour, gender, ethnicity, nationality or religion, and may even include differences in ways of thinking. (Buhler, 1993:17-19).

Greater workforce diversity will undoubtedly present managers and human resource practitioners with new challenges, but it must also be recognized that diversity could contribute to organization effectiveness and responsiveness. Diverse populations have different experiences, insights, values and approaches to workplace issues, resulting in different perspectives and alternative solutions to work-related problems (Wilson, 1994: 27). Cox and Blake (1991:45-56) argue that diversity could be a source of greater creativity and innovation and enhanced organization flexibility.

Mary McEnrue (1993:18-29) is convinced that managing diversity is essential, "not simply something to do because it is nice....but a competitive necessity ...a business imperative ...a strategic priority". In her studies of the strategies of American companies in Los Angeles to manage workforce diversity, respondents cited benefits like a better understanding of customer needs, improved employee relations, enhanced public image and lower labour costs as the results of the effective management of diversity. The author states however, that the potential benefits of workforce diversity are substantial but not automatic: the process of creating and capitalizing on diversity must therefore be carefully managed.

Daniel (1994:14) supports this point of view. He is of the opinion that South Africa has no choice but to harness the talents and ideas currently available in its diverse labour pool. Unless diversity is turned into an asset, it might become our downfall.

Most human resource practitioners define managing diversity within the context of creating a work environment in which obstacles to the realization of human potential are removed. Table 1 indicates some such definitions by various authors.

For the purpose of this article, we take the concept of managing diversity to refer to management processes aimed at the development of a work environment in which individual differences are accepted and valued, and management policies and practices aligned to enhance inclusiveness of all employee groups, in order to optimize economic performance. 


\section{Table 1: Some definitions of managing diversity}

\begin{tabular}{|l|l|}
\hline Fuhr (1994:10) & $\begin{array}{l}\text { It has to do with creating a working environment in } \\
\text { which everyone has a true sense of belonging and which } \\
\text { removes the barriers that have hindered the fulfillment of } \\
\text { human potential. }\end{array}$ \\
\hline Daniel (1994:14) & $\begin{array}{l}\text { Managing diversity is a process for developing an } \\
\text { environment } \\
\text { - that fosters awareness, value and acceptance of } \\
\text { individual differences, } \\
\text { - that gives employees opportunities and judges them } \\
\text { fairly on their talents and contributions, } \\
\text {-thereby attempting to address expectations and remove } \\
\text { or reduce biases and stereotypical behaviour. }\end{array}$ \\
\hline Wingrove (1993:8) & $\begin{array}{l}\text { This concept is based on the premise that every } \\
\text { individual is unique, bringing his/her special talents and } \\
\text { attributes to the workplace to be utilized for the benefit of } \\
\text { the greater whole. }\end{array}$ \\
\hline Thomas (1996:10) & $\begin{array}{l}\text { Managing diversity can be defined as a planned, } \\
\text { systematic and comprehensive managerial process for } \\
\text { developing an organizational environment in which all } \\
\text { employees, with their similarities and differences, can } \\
\text { contribute to the strategic and competitive advantages of } \\
\text { the organization, and where no one is excluded on } \\
\text { account of factors unrelated to productivity. }\end{array}$ \\
\hline
\end{tabular}

\section{A STRATEGIC FRAMEWORK FOR MANAGING DIVERSITY}

A literature search to find appropriate models for the management of diversity meets with little success. Such a model would be useful to compare the management of diversity in the countries concemed, namely Israel and South Africa.

Ann Morrison (1992:42-48) proposes a 5-step model for the development of diversity management programmes. This model is however only of limited use, as it is meant to be a basic instrument for identifying so-called best practices for the management of diversity. McEnrue (1993:18-29) in her research describes a number of strategic dimensions that form the basis of diversity management programmes of large organizations in Los Angeles, but does not integrate these into a comprehensive 
model. The relevant information in the literature is of fragmentary nature and does not provide an adequate framework for the purpose of management planning. An effort to integrate the information found into such a model is depicted in Figure 1.

Figure 1: An integrated strategic framework for the management of diversity

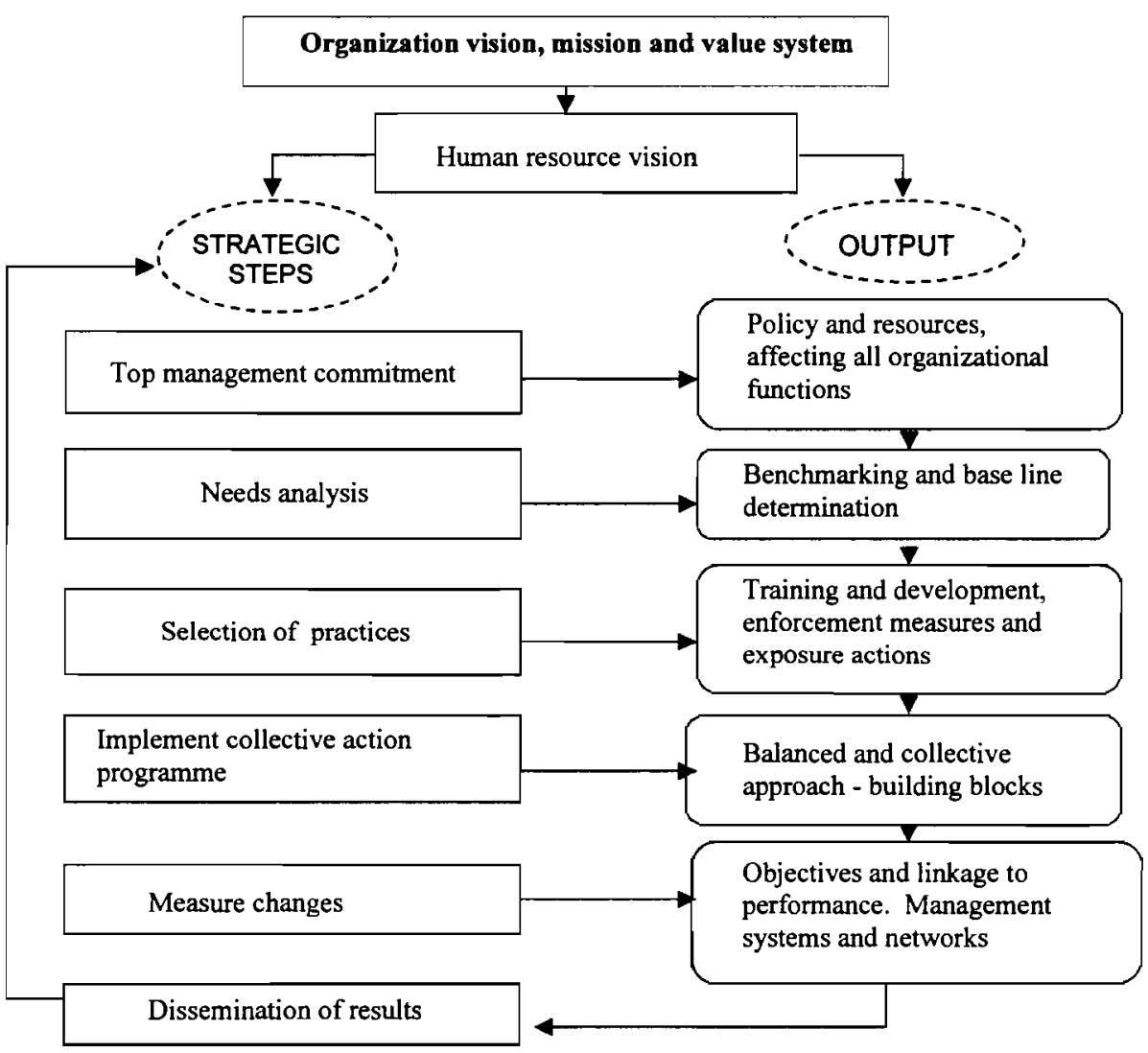

(Source: Petersen, 1998: 70)

This integrated framework serves as a guideline to managers in their efforts to manage diversity. It focuses on the following: 
The vision, mission and value system of the enterprise as the point of departure for managing diversity. These concepts normally reflect the personal philosophy and values of the chief executive officer and top management, and describe the core values of the organization.

The human resource vision: This is a subset of the organization's overall vision, and articulates its human resource dimension in specific terms. As far as diversity is concemed, values like respect for cultural differences, unique contributions and equal opportunity should be included.

Strategic steps and outputs: The following strategic steps and resultant outputs are important.

- Obtain top management commitment with a view to ensuring supportive policy and practices, as well as the necessary financial means to execute the policy. Needs analysis, including processes like measurement of perceptions, obtaining information and statistics, and benchmarking.

Selecting the best combination of practices to support the management of the diversity effort. These fall mainly into the categories of training and development interventions, enforcement practices and exposure activities. These practices may also include changes to existing practices, e.g. performance measurement and reward systems. The emphasis must fall on the right mix of practices, best suited to the organization's needs. It would appear that the current infatuation with so-called generic "best practices" is not supported by empirical facts (Morrison, 1992:43).

Implementation of the collective action programme: The prime requirements for such a programme are that it should be a balanced approach founded on a thorough needs analysis, and include the right mix of practices. Appropriate building blocks should be utilized to ensure the continuity of the programme.

Dissemination of results is necessary for periodic review and corrective action, in order to meet newly identified needs.

As mentioned above, this proposed framework is offered as a guideline for management use. It goes without saying that dialogue and consultation with diverse groups are essential to ensure success. 


\section{MANAGING DIVERSITY IN ISRAEL}

The management of diversity in Israel is manifested at two levels, i.e. at macro-level as managed by the Israeli authorities and at micro-level, in the efforts of an individual enterprise to manage its diverse workforce. This means that managing diversity consists of first order and second order interventions.

Figure 2: The process of managing diversity in Israel

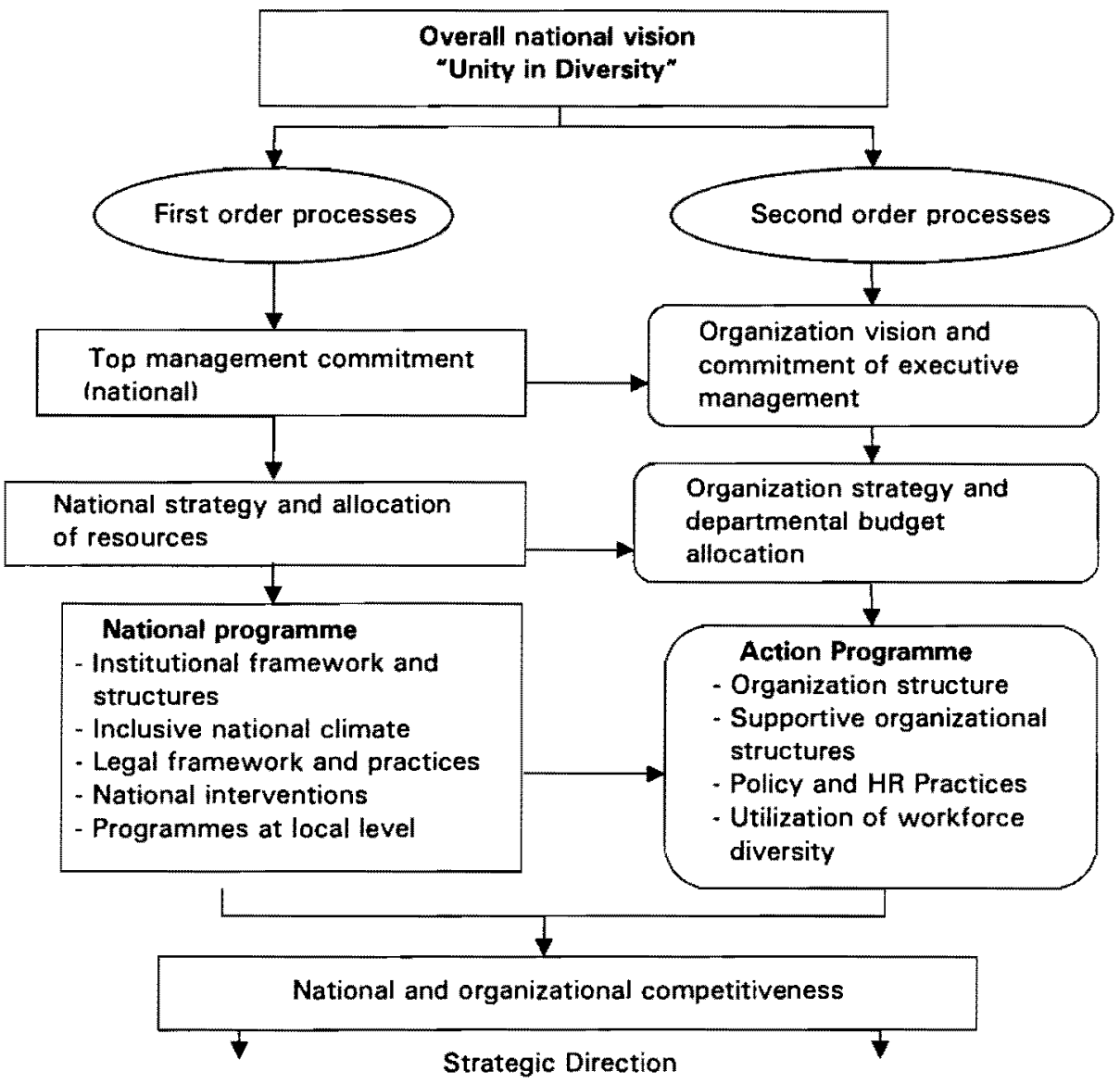

(Source: Petersen, 1998:239) 
First order management of diversity entails a comprehensive programme by the authorities, in order to absorb a great number of diverse immigrants into Israeli society and to transform these people into a new national identity.

- Second order management of diversity refers to the efforts of the Israeli business community to manage a diverse workforce and to turn this into a strategic advantage. This situation is illustrated in Figure 2.

The first order process of managing diversity consists of a national programme by the authorities, aimed at integrating diverse immigrant groups into a collective identity. The result of these efforts is that it sets the scene for the management of diversity at the individual enterprise level, i.e. the second order management of diversity. The nature of these two processes is next briefly discussed.

\section{The first order process of managing diversity}

As illustrated in Figure 2, the point of departure for the first order management of diversity is a national vision of diversity as a strategic advantage.

The vision of Israel is embedded in its Zionist ideals of national reconstruction and renaissance, founded on a religious base. It focuses on the themes of Jewish solidarity and the re-establishment of a collective identity, with the objective of including the Jewish nation in the family of nations (Eisenstadt, 1985: 86).

This national vision is the driving force behind a programme of strategic interventions having the following central themes.

\section{National efforts to reconstruct Jewish symbols and traditions}

The resurrection of a "dead" language, Hebrew, as a common national language. Hebrew is today a language of international significance, that meets the requirements of modern science and technology. It also forms a primary binding factor in the cultural structure of Israeli society.

The re-establishment of age-old Jewish traditions and customs. This played an important role in the reconstruction process and formed the basis for the new identity of a new generation of Israelis. As a result, a unique cultural format has developed over time, with a peculiar balance between the demands for tradition and modernity. This contributes to the reduction of friction between the religious and secular groups in Israeli society. 
A need for new themes in the enhancement of a new collective identity developed over time. This resulted in the development of new symbols and legends, like the image of the toughness and courage of the Israeli soldier and self-sacrifice in the defence of a beleaguered " nation under arms". In this way the image of the "sabra" developed as a symbol of the new generation of Israeli's. "Sabra" refers to a prickly pear and is supposed to describe the Israeli psyche - tough on the outside but sweet inside.

The efforts to reconstruct Jewish traditions and customs were very successful and this has undoubtedly contributed to the fact that Israel today stands out as a nation characterized by cultural richness and unique identity.

\section{National-educational interventions}

Israel is a multi-cultural and conflict-ridden society. This heterogeneity had a special impact on the development of the educational system. The Israeli authorities were faced with the challenge of balancing their need to build a nation from immigrant groups of diverse origins, at the same time accepting the legitimacy of their cultural pluralism. In addition, a decision had to be taken regarding the nature of an acceptable educational system for the Arab minority, taking in consideration their national and religious aspirations.

As a result an educational system developed over time that is characterized by the following features:

The initial approach to education, based on the melting pot principle, was replaced by a philosophy of multi cultural education. This new orientation entails creative curricula, with the emphasis on the uniqueness of ethno-cultural differences. The training programme of teachers was adapted with this in mind and now includes compulsory courses in concepts such as peaceful co-existence, majority-minority relations and workshops in heterogeneous teaching. State education for Arab minority takes cognisance of the needs of the Arab community and its cultural values (Resh \& Kfir, 1990:13).

With regard to language, it was decided to include both Arabic and Hebrew in the curriculum, effective from the first grade. 
It may therefore be concluded that the ideological shift to multi-culturalism in education has resulted in a growing sensitivity to ethnicity and diversity, with teachers now being trained to deal with this in the classroom.

\section{The role of the Israeli Defense Force (IDF) as integrating factor}

The functions of the IDF are defined to include more than purely military tasks. The IDF is used very effectively for purposes of nation-building and plays a significant role in the integration of diverse groups in Israeli society.

Military service is the passport or "rite de passage" to Israeli society. It is widely accepted that national service has the most important forming effect of all national experiences, and that real integration into national life occurs during the years of national service (Cohen, 1995:245).

The nation-building role of the IDF includes tasks like compensatory training for Jewish immigrant groups from disadvantaged communities (adult education, literacy training), provision of temporary accommodation for immigrants, and special upliftment programmes for marginalized youths (drop-outs). In so doing the state harnesses the tremendous capacities of the IDF for non-military use as a resource for the integration and utilization of human diversity.

\section{A national strategic absorption programme}

The large-scale absorption of immigrants into Israeli society would not be possible without the policy action and resources of the state. The Ministry of Immigrant Absorption and the Ministry of Trade and Industry play an important role in this regard (Israel Government Yearbook, 1991: 262-272).

The Ministry of Immigrant Absorption is responsible for the economic, vocational and social integration of immigrants during their first three years after arrival. It formulates related policy and co-ordinates the activities of public institutions which play a supportive role.

The prime function of the Ministry, for the purpose of this article, is the employment and placement of immigrants. It liaises with employers, monitors the labour market and is responsible for services like psychometric testing and vocational certification of new immigrants. It also promotes vocational training and retraining of immigrants, is responsible for language teaching schools, and runs four regional centers of career counseling and referral of prospective employees. The Ministry undertakes special 
projects in co-operation with employers, for example, training and development of entrepreneurs and a centre for the absorption of scientists.

The Ministry of Trade and Industries contributes significantly to the utilization of diverse talents in the labour force, with special reference to new immigrants. It operates a number of important projects, e.g. the so-called technology incubator projects. The incubator programme is a national intervention, aimed at stimulating technological growth of the high-technology industry. This approach entails the establishment of projects, utilizing the inventions or specialized knowledge of immigrant groups, with the ultimate objective of producing viable commercial products and forming commercial companies. The stress falls on developing the entrepreneurial competence of new immigrants (e.g. from the ex-Soviet region), as ownership of such companies will eventually go over to these project team members. Not only have thousands of job opportunities been created through this programme these projects also serve as a hothouse for new ideas and technologies.

Municipal authorities play a supportive role in the integrating of immigrants into economic and social life. Work creation projects are undertaken by some (e.g. Artist Village in Jerusalem), research is done into the needs of immigrants, support is given to prospective entrepreneurs and services like training and information are provided (JDC Brookdale Institute, 1992). It may be concluded that local authorities serve as an extension of national policies for the integration of diverse population groups.

These interventions by the state emphasize the strategic importance of diversity in the community. As a result the value of diversity is acknowledged at national level and this sets the scene and creates an underlying structure for the management of diversity at organization level.

\section{The second order processes for the management of diversity in Israel}

It is clear from the foregoing outline that the first order processes create a foundation for the management of diversity at individual enterprise level. It is also interesting to note that the processes show remarkable similarities to the strategic framework proposed in Figure 1.

A literature search, supplemented by a survey of a number of top Israeli companies $(n=26)$, indicates that Israeli enterprises are highly pragmatic in their approach to managing diversity (Petersen, 1998:280). The results of the survey are summarized below. 


\section{Strategic Direction}

Little evidence can be found that Israeli managers have formal strategic plans for managing diversity - this corresponds to the fact that Israeli managers have a more informal style of management than their South African counterparts. It is, however clear from the survey that the respondents do generally utilize diversity quite effectively.

\section{Utilization of diversity as strategic advantage in local markets}

There are many examples of how Israeli companies utilize diversity in local markets. Black Ethiopian Israelis are often used for marketing products in their closed community, Israeli Arabs are employed to penetrate residentially segregated Arab markets, and ultra Orthodox Israelis promote/sell kosher products in that segment of the market.

\section{Utilization of diversity as strategic advantage in international business activities}

Like South Africa, Israeli companies find that intemational and regional markets become more accessible as a result of peace initiatives. Israeli managers utilize their diversity in a very pragmatic way for the purpose of establishing themselves in these markets.

Many second and third generation Israeli immigrants have good business contacts, family relations and a sound knowledge of the business culture of their country of origin, and thus access to business opportunities in the markets of those regions.

A good example is the large number of Russian immigrants who arrived in Israel recently. They still have family connections in Russia, a thorough understanding of business conventions there, and naturally know the Russian language. This diversity is effectively utlized by companies as strategic advantage to operate in the Russian business environment. Many similar examples were found in the study, including organizations which deliberately recruit diversity, with a view to promoting international business ventures. Israeli companies are highly export-orientated and make good use of their diversity for this purpose.

Israeli Arabs stand with their feet in both the Israeli and the Arab cultures. It therefore makes good business sense to use them as intermediaries for doing business 
in regional markets like Jordan and Egypt, and many Israeli companies are making good use of this example of diversity.

Human resource systems and practices for managing diversity

Respondents are generally convinced that their human resource systems and practices support the management of diversity. The principle of flexibility is embodied in most human resource practices. Respondents who employ large numbers of female workers use flexitime widely, and have implemented special working arrangements for working mothers and single parents. Day-care centres in the workplace are commonplace. Some employers even allow mothers to work shorter hours for a period of two months after the birth of their babies.

Special arrangements are widely applied to accommodate religious differences. Synagogues and kosher restaurants are commonly found on the premises, social functions are arranged separately for ultra Orthodox groups, and employees are not used for tasks in foreign countries if they have dietary requirements that cannot be met there.

The same measure of flexibility can be found in the remuneration system of some companies. Remuneration systems are adapted to the diverse needs of especially scarce categories of employees, like young computer engineers, who prefer to receive more cash and fewer social benefits, e.g. pension contributions.

Recruitment practices are sensitive to the advantages of diversity. Thus one respondent prefers to recruit female Indian Israelis for wiring tasks in the production of certain micro-electronic components, as these workers have special dexterity possibly of a cultural nature. Special travel arrangements are made for such workers who live in rural areas.

These examples of human resource practices and systems supportive of managing diversity are but a few of the total number reported in the study. Unique practices for the development of disadvantaged employees (e.g. third - world immigrants) were also reported. These examples indicate a built-in sensitivity to diversity and its benefits. 
Organization climate and managing diversity

Survey respondents reported that average Israeli companies have created a work climate that is conducive to managing diversity. Most employers focus on the talents and performance of employees. They agree that the Israeli business culture is characterized by tolerance and acceptance of differences. This is attributed to factors like the collectivist kibbutz system, the binding effect of military service and the increase in intergroup marriages. The combined effect of these factors permeates all institutions of the community, specifically the culture of the enterprise. Despite the positive organization climate reported in the study, employers agree on one area of concern: Israel is a chauvinistic society and the talents of women employees remain underutilized.

It may be concluded that the business climate of Israeli companies is generally positive for managing diversity, not so much because of formal strategies or business plans as the combined effect of the first and second order processes at work. Within the context of the organization, managers do not think in terms of the cultural differences of the workforce, but focus on the potential contribution of people and their diverse abilities to organizational and individual objectives.

\section{SOME APPLICATIONS FOR SOUTH AFRICA}

The management of South Africa's human diversity is a complex task not to be underestimated. It should be viewed within a specific historic context and a particular set of circumstances, and it requires a unique problem-solving approach. A review of the Israeli approach to managing diversity however provides us with some lessons that can also contribute positively to the South African situation. The following recommendations may well prove useful to South African decision makers.

\section{The need for an integrated national strategy for managing diversity}

The above research results indicate that this is the most important lesson that South Africa could learn. The Israeli success is the result of the interaction of all the various processes of managing diversity, especially the national vision and related policy interventions for the management of diversity, which create the right climate and establish the national value of appreciation of diversity. This in turn lays the foundation for managing diversity at the level of the individual enterprise. 
Although some aspects of a national strategy are discemible, South Africa lacks a holistic approach that includes visionary leadership, an integrated programme of policy interventions, an adequate superstructure and appropriate management systems. One particular element of managing diversity, affirmative action, is overemphasized and does not have a long-term focus.

In our opinion, a long-term integrated strategy for managing diversity could have the following positive effects in South Africa.

It could contribute to a national climate conducive to managing diversity. Such a national climate would motivate business leaders to manage diversity in the workforce effectively, with emphasis on gaining a competitive edge. A favourable climate in the national context, presupposes a work environment in which all obstacles to realizing human potential are removed. This would require a commitment by the authorities at national level to create a strategic framework for the management of South Africa's total rainbow nation, which would result in the empowerment and effective utilization of all groups of employees.

A recent survey of South African business leaders with regard to the role that government should play in affirmative action, clearly showed that most respondents would prefer it to play no role at all. They reasoned that the government should at most promote corrective action through incentive measures, e.g. tax rebates (Jeffery, 1996: 11-13). This kind of argument is compatible with the strategy outlined above.

- A shift of emphasis towards a long-term approach for managing diversity, could help to counteract the probable negative effects of affirmative action. Forced affirmative action is at present creating resistance to efforts of diversity management. The need for affirmative action is irrefutable, but the danger of a hardening of attitudes is growing due to the present short-term approach. This could eventually do irreparable damage to existing goodwill amongst those negatively affected by a politically inspired, short-term drive for affirmative action.

It is hoped that emphasis on a long-term strategic approach to diversity would result in the establishment of a national culture of respect for the talents of all workers and that this would in turn motivate employers to elevate the management of diversity to the level of strategic priority.

- A comprehensive strategy should include national policy interventions, similar to those found in the Israeli approach. Examples are the creation of national symbols with a bonding effect, an education system based on respect for 
differences, with teachers who trained to manage diversity in the classroom, and innovative cultural practices to enhance a new collective identity. Our success in this regard has been limited, possibly due to the novelty of the South African situation,

- The short-term emphasis on affirmative action is partly to blame for the current net skills loss caused by the emigration of trained labour. Appropriate national policy intervention should be formulated soon to prevent the further outflow of such skills.

\section{Utilizing diversity as strategic business advantage}

The study of the management of diversity in Israel reflects a number of excellent examples of how diversity in the workforce should be utilized as strategic business advantage. Very little evidence exists that South African companies are utilizing diversity in such an effective way. The Israeli approach of using representatives from specific communities for the purpose of marketing, could also be applied to South Africa and African markets.

\section{The development of a South African based management approach to managing diversity}

This study has served to provide evidence of a unique Israeli management approach, based on factors like the collectivism of kibbutz culture. In this style of management opportunities are provided for group work and high levels of social interaction, natural leadership is emphasized and recognition is given to the technical ability and integrity of workers. It may be concluded that this management approach is not only appropriate for the Israeli workplace but in fact best suited to the diverse nature of its workforce.

South Africa is challenged to develop a similar indigenously based management style, suited to the local situation. A South African management approach should incorporate such aspects as the community concept, which brings to the fore images like supportiveness, cooperation and communalism (Christie, Lessem and Mbigi, 1993:123). Although the issue of an appropriate Afrocentric approach to management is already receiving attention in academic and professional circles, there is little evidence that business performance would be enhanced in this way. In-depth research is urgently needed to develop indigenous models in this context. Such models will have to take into account factors like ethnic differences in the workforce, the diverging interests of workers, biases of the past, racial polarization and even 
clashing ideologies. The acid test will eventually be whether a South African-based style of management will enable South African businesses to compete in a highly competitive international environment.

\section{Development of an organizational climate in which diversity can be effectively managed}

One particular fact that stood out during the above survey, was that the organizational climate of the average Israeli business organization contributes positively to the management of diversity. Three particular aspects of the organizational climate may be mentioned:

- $\quad$ openness to and awareness of the needs of diverse groups,

- $\quad$ tolerance of differences, and

- situational adaptability which confirms the value of diversity.

The climate in Israeli organizations unmistakably reflects the broader values of the community. The Israelis, since the inception of statehood, have had to rely on the contributions of all groups for survival. As mentioned earlier, these values have their origin in a national vision and collectivist system, based on equality of and respect for individual contributions, together with tolerance and understanding of human differences.

The positive nature of the climate within the typical Israeli enterprise is characterized by the readiness to make comprehensive changes to management systems and practices in order to meet the needs of diverse population groups. This readiness to adapt communicates a culture of inclusiveness to employees.

The application of this principle to South Africa depends on the intrinsic value of inclusiveness. It emphasizes a strategic vision to strive for an organizational climate in which all employees are empowered to realize their potential. The Israeli organizations in this study demonstrated that they are willing to invest in pragmatic, visible measures to promote the management of diversity - something which they practise rather than preach.

\section{CONCLUSION}

The study of managing diversity in Israel indicates an important fact: that it must be viewed as a total process. The primary role-players in this process are the national 
authorities and the individual enterprises. They need to work together as partners in order to co-ordinate their efforts into viable national and organizational objectives. At enterprise level, the study revealed the importance of inclusiveness. This brings to the fore the fact that the emphasis must fall on the effective management of people: managing diversity is all about the effective management of people and their individual talents for the common good of the organization and all its stakeholders (Human, 1996: 4).

\section{REFERENCES:}

1. BUHLER, P. (1993), "Managing in the $90 \mathrm{~s}^{\prime \prime}$, Supervision, 7-19.

2. CHRISTIE, P. LESSEM R. and MBIGI, L. (ed). (1993, "African Management: Philosophies, Concepts and Applications", Knowledge Resources, Randburg.

3. COHEN, S.A. (1995), "The Israel Defence Force (IDF): From a 'Peoples Army' to a 'Professional Military", Armed Forces and Society. 21(2) $237-$ 254.

4. COX, T.H. and BLAKE, S. (1991), "Managing Cultural Diversity: Implications for Organizational Effectiveness", Academy of Management Executive, 5(3), 45-56.

5. DANIEL, R. (1994), "Diversity: it's Good for Business". Human Resources Management, 14-17.

6. EISENSTADT, S.N. (1985), The Transformation of Israeli Society. Westview Press, Calorado.

7. FUHR, I. (1994), "Worlds Apart: Managing Workforce Polarisation", People Dynamics, 8-13.

8. HIRSH, E.(ed). (1993), Facts about Israel. Israel Center, Jerusalem.

9. HUMAN, L. (1996), "Diversity During Transformation". Human Resources Management, 12.

10. MINISTRY OF EDUCATION AND CULTURE, INFORMATION CENTER. (1991), Israel Government Yearbook 5750. Jerusalem.

11. JDC BROOKDALE INSTITUTE. (1992), The Road to Successful Absorption. Research Report. Lod.

12. JEFFERY, A. (1996), "Business and Affirmative Action". Report. SouthAfrican Institute of Race Relations. Johannesburg.

13. McENRUE, M.P. (1993), "Managing Diversity: Los Angeles Before and After the Riots", Organizational Dynamics, 21, 18-29.

14. MORRISON, A. (1992), "Developing Diversity in Organisations, Business Quarterly, 57(1), 19-23. 
15. PETERSEN, R.J. (1998), Die Bestuur van 'n Diverse Werksmag in die Israelse Besigheidsomgewing en Paralelle Toepassings vir Suid-Afrika. Unpublished doctoral thesis, University of Pretoria.

16. RESH, N. and KFIR, D. (1990), Desegregation and Effective Schools: Contradictory and Complementary Interventions. Report. The NCJW Institute for Innovation in Education. Hebrew University. Jerusalem.

17 THOMAS, A. (1996), Beyond Affirmative Action. Knowledge Resources, Randburg.

18. WILSON, P. (1994), "Cultural Diversity: An Organisational Asset", Public Manager, 23, 27-30.

19. WINGROVE, T. (1993), Affirmative Action: $A$ "How" Guide for Managers. Sigma Press, Pretoria. 